SISOMOS

AMERICANOS

Revista de Estudios

Transfronterizos
Volumen XXI, número I,

enero-junio de 2021

Recibido: 3 de febrero de 2020

Aprobado: 1 de febrero de 2021

\title{
Categorías zombis en la política exterior chilena de la transición democrática* $^{*}$
}

\section{Zombie categories in foreign policy during Chile's democratic transition}

\author{
Cristián Fuentes V.** \\ Universidad Central de Chile.
}

\begin{abstract}
Resumen
En la política exterior de la transición democrática chilena (1990-2010) se utilizaron categorías que pueden ser denominadas zombis, pues su aplicación práctica difiere de un significado original casi vacío. El regionalismo abierto, la prioridad latinoamericana y la política de Estado surgieron de imposiciones hegemónicas, influencias corporativas y tradiciones muy arraigadas que delinearon una estrategia de inserción internacional sustentada en el comercio global, sin preferencias regionales. Este artículo utiliza el enfoque constructivista para analizar cómo las tendencias políticas predominantes en el plano doméstico adoptaron un carácter consensual simulado para evitar el conflicto mediante fórmulas aplicadas por el presidente de la República, actor constitucional casi único en la toma de decisiones en el ámbito externo y símbolo de la unidad nacional.
\end{abstract}

Palabras clave: política exterior, transición democrática, categorías zombis.

"Este artículo es resultado del proyecto "Política exterior de la transición chilena (1990-2012)", financiado por la Universidad Central de Chile (2019-2021).

${ }^{* * *}$ Profesor de Historia y Geografía, Universidad Metropolitana de Ciencias de la Educación. Magíster en Ciencia Política mención en Relaciones Internacionales, Pontificia Universidad Católica de Chile. Estudios de doctorado en Estudios Americanos, Instituto IDEA, USACH. Profesor, Universidad Central de Chile, Escuela de Gobierno y Comunicaciones, carrera de Ciencia Política. Dirección postal: Lynch Sur 304, La Reina, Santiago. Correo electrónico: crfuentes47@gmail.com. ORCID: https://orcid.org/0000-0003-4280-0391 


\begin{abstract}
Categories that can be referred to as 'zombie' were used in the foreign policy of the Chilean democratic transition (1990-2010). The term 'zombie' is used to describe them because their practical application differs from an original definition that is almost meaningless. Open regionalism, Latin American priority and long-standing State policy arose from hegemonic impositions, corporate influences and deep-rooted traditions that delineated a strategy of international insertion based on global trade that was lacking any regional preferences. This article uses the constructivist approach to analyse how the dominant domestic political tendencies adopted a simulated consensual character to avoid conflict through formulas applied by the President, who represents an almost unique constitutional actor in decision-making processes in the external sphere and a symbol of national unity.
\end{abstract}

Keywords: foreign policy, democratic transition, zombie categories.

\title{
Introducción
}

Nos permitimos pedir prestado a Ulrich Beck (2004) el concepto de categorías zombis. Aunque la noción original se refiere a que en la era de la globalización el Estado-Nación ya no existe como fue concebido en la modernidad, pues la idea-fuerza del cosmopolitismo delinea un nuevo escenario de poder que ya no puede ser interpretado ni comprendido según las antiguas categorías, dinámicas y reglas del juego (Beck, 2004), constatamos que ciertas expresiones sobreviven en nuestros días como sombras sin contenido preciso ni márgenes claros. Tales expresiones continúan siendo utilizadas sin ser capaces de explicar o, al menos, ayudar a entender los asuntos públicos, trayendo como resultado instituciones zombis, ineficaces para las tareas que estaban destinadas a cumplir.

¿Es factible aplicar estas categorías en la política exterior chilena de la transición democrática? La reflexión de este sociólogo alemán nos sirve de inspiración para emplear el concepto zombi en un sentido similar, aunque no idéntico, pues cualquier noción puede ser desprovista de su significado y en la praxis política ser usada a voluntad de quien la domina, tal como un brujo del vudú puede despertar a un muerto y utilizarlo como esclavo. Ello nos permite explorar como hipótesis que el regionalismo abierto, la prioridad latinoamericana y la política de Estado, son expresiones cuya aplicación en diversas épocas o ciclos del período de transición a la democracia (19902010) difiere de su sentido original, transformándose en categorías zombis. Dicho de otra manera, concebir la política exterior de la transición como un consenso nacional sin fisuras, conformado por la inserción plena de Chile en la globalización, a partir de América Latina, corresponde más bien al esfuerzo por dotar de amplitud y pluralismo al proyecto hegemónico impuesto desde el fin de la dictadura.

Su concreción aparece de una manera distinta al discurso oficial, situación que podría ser calificada como travestismo; vale decir, la práctica consistente en ocultar la 
verdadera apariencia de alguien o algo. Sin embargo, la condición que estimamos más importante es aquella que aprovecha una cáscara vacía para llenarla con otros contenidos. En este caso, referido a la adhesión al neoliberalismo sin reconocerlo, justificando desde el pragmatismo una prioridad que no existe, un regionalismo vacío y una política de Estado que no se basa en un consenso pleno.

Desde 1990, la inserción internacional del país fue estableciendo una clara preferencia por el comercio global, apartando los matices que justificaban la prioridad por América Latina, ya que salvo un primer momento (1990-1992) en que se firmaron Acuerdos de Complementación Económica (ACE) con la mayoría de los Estados de la región y cuya participación en los espacios políticos existentes demostraron el interés por los asuntos del entorno geográfico, ello fue perdiendo importancia hasta ser reemplazado por la suscripción de Tratados de Libre Comercio (TLC), más amplios y de mayor profundidad que los ACE, con nuestros principales socios comerciales, por lo que Chile se abstuvo de ejercer cabalmente el regionalismo.

En el discurso oficial, la inserción internacional de Chile se entendió como un importante componente de la estrategia de desarrollo nacional, dentro de la cual los acuerdos bilaterales cumplirían el objetivo de amparar el comercio exterior en normativas y disciplinas comprometidas mediante tratados. Además, la apertura comercial se comprendía como compensación para un mercado interno estrecho, como parte de una política macroeconómica cuidadosa de los equilibrios globales y de la asignación de recursos basada en los mecanismos de mercado, en convergencia con la fase de globalización económica que vivía el mundo (DIRECON, 2009).

El carácter pactado de la transición chilena restringió los acuerdos a la élite gobernante y a las contraélites democratizadoras (Rovira, 2007). La élite política nacional (políticos profesionales, tecnócratas y tecnopols $)^{l}$ estaba dividida en su apreciación internacional, con un fuerte núcleo tradicional poco interesado en los asuntos internacionales, afectado por un enraizado parroquialismo, o prevalencia de una mirada hacia adentro, que se contradecía con el modelo de apertura económica. Sin embargo, las necesidades políticas obligaron a proyectar al exterior los elementos fundamentales del proceso de transición.

La transición a la democracia tuvo que hacerse cargo de la necesaria reincorporación a una comunidad global que había rechazado a la dictadura del general Augusto Pinochet, y que se encontraba sujeta a profundos cambios, tales como el fin de la Guerra Fría, el poder militar unipolar de Estados Unidos y la consolidación de la dinámica de crecimiento del Asia Pacífico. Tal panorama fue constituyendo una doble transición, que determinó el peso de las fuentes internas y externas de la política exterior, al tiempo

\footnotetext{
${ }^{1}$ influyente élite tecnocrática de la transición estaba integrada por profesionales jóvenes con estudios de posgrado en el extranjero, en su mayoría en Estados Unidos. Estos tuvieron la oportunidad de protagonizar diversas reformas políticas, cuya orientación devino en una pugna creciente con la clase política tradicional (Silva, 2010). Los tecnopols son tecnócratas dedicados no solo a la gestión, sino que también a propiciar acuerdos y generar reformas (Joignant y Güell, 2011).
} 
que relevó los factores domésticos, debido a que formaban parte de la mudanza de régimen, característico de la dinámica transicional (Lasagna, 1996).

Como se desprende del conjunto de esta investigación, las orientaciones principales del comportamiento externo de Chile en estos años adoptan un carácter consensual simulado, puesto que existen visiones equívocas y disímiles, tanto en la coalición gobernante como en la oposición, las cuales son resignificadas por el enfoque predominante, aunque conserven su denominación primigenia. Entre estas perspectivas antagónicas encontramos la centralidad latinoamericana versus la apertura sin regionalismo al resto del mundo, el modelo exportador basado en materias primas o en productos con mayor valor agregado, la globalización neoliberal y el desarrollo (Pizarro, comunicación personal, 16 de septiembre, 2013), e, incluso, la misma idea de consenso.

Con la imposición del acuerdo se evita el debate y el conflicto queda apaciguado por fórmulas aparentemente consensuales, justificación y a la vez obligación que comprometen las opiniones particulares para que sean aceptadas como válidas, todo ello aglutinado alrededor de la figura del Presidente de la República, actor políticoinstitucional que concentra constitucionalmente la toma de decisiones en política exterior. De aquí también provienen las reglas que legitiman el discurso, elaborado a partir de funcionarios y académicos teóricamente actualizados; no obstante, prevalezcan en el accionar del Estado las perspectivas más tradicionales.

El bilateralismo, el realismo y el balance de poder -entendidos como ideas construidas por la élite dominante del siglo XIX chileno, con el objeto de construir una identidad nacional en contraposición con los intereses de sus vecinos y no como rasgos esenciales del comportamiento de los Estados, como afirma el realismo clásico-, así como la herencia autoritaria y un modelo económico neoliberal corregido o heterodoxo, junto a un progresismo limitado ajustado a la democracia que reemplazó a la dictadura civilmilitar (Garretón, 2012), priman cuando se trata de actores tales como las Fuerzas Armadas (Flisfisch, comunicación personal, 24 de julio, 2013), la diplomacia profesional y los grupos de presión empresarial pro mercado. Por ello, cuando se trata de dar cuenta de un panorama exterior marcado por ciertas tendencias consolidadas después de la Guerra Fría, los factores intervinientes en la política doméstica se alinean en el mismo sentido y producen resultados concurrentes con el escenario de doble transición, democrática interna y pos-Guerra Fría externa (Maira, comunicación personal, 8 de noviembre, 2013), en el cual se deben tomar las decisiones.

\section{Metodología y herramientas teóricas para el análisis}

En el desarrollo de este artículo se aplican herramientas metodológicas de carácter deductivo y cualitativo mediante un análisis crítico de los fenómenos y del contexto indicado en la hipótesis. La interpretación de la política exterior del período inicial de la transición a la democracia en Chile y de cómo se tomaban las decisiones, surge del 
contraste de los testimonios de actores clave con el discurso oficial, presente en la bibliografía indicada.

Se ha elegido el enfoque constructivista en pos de superar aquella mirada del realismo clásico que concibe la realidad social como una estructura material dada y no como una construcción. En este sentido, se intenta desarrollar una epistemología centrada en la hermenéutica, la historicidad, y en el estudio de las ideas y del discurso (Arriola, 2013). No obstante, debemos reconocer que hoy esa contradicción se ha debilitado, por la convergencia en las agendas de investigación (Adler, 2010) y por un cierto "eclectisismo analítico" en el debate teórico (Rudra y Katzenstein, 2010), que pone a la construcción social internacional como un "lugar normal" (Adler, 2010). Además, el estudio de los procesos de construcción de la identidad y de sus consecuencias estratégicas, el poder, la estrategia militar, las prácticas y los hábitos (Adler, 2013), ha hecho surgir un constructivismo realista que trata de explicar cómo nacen normas en contextos donde priman relaciones de poder (Barkin, 2010).

El constructivismo nos sirve para comprender mejor la naturaleza construida socialmente de las categorías zombis, entendidas dentro de unas relaciones internacionales formadas por vínculos entre agentes, procesos y estructuras sociales, junto a instituciones que son entidades cognitivas sin existencia independiente de las ideas de los actores sobre el funcionamiento del mundo (Wendt, 2005). En tal perspectiva, las percepciones (opiniones) humanas históricas y culturales construyen el sistema internacional a partir de relaciones de poder, por lo que las ideas, identidades e intereses -consideradas como lo inmaterial-son más importantes que lo material.

Esto se entiende solo a través de un tipo de conocimientos, denominados "significados intersubjetivos", porque al ubicarse en "lugares compartidos" (memorias colectivas, conceptos compartidos, interpretaciones colectivas, procedimientos e instituciones) constituyen más que la suma de creencias individuales, puesto que "tienen vida propia" en una realidad dependiente del significado y de la acción humana, donde los seres sociales no pueden ser separados del contexto que conforma quienes son (Vitelli, 2014). Tal visión teórica otorga un papel protagónico a las identidades, es decir, a las concepciones hacia uno mismo y hacia los demás actores. Estos no tienen una identidad unívoca, sino que reciben diferentes identidades en función de quién les defina, aunque la versión identitaria más importante es la que el actor define para sí mismo (Wendt, 2005).

La autodefinición se establece a partir de las normas constitutivas formales e informales que precisan la pertenencia a un grupo, los objetivos sociales compartidos por los miembros del grupo, las comparaciones relacionales definidas por la identidad del grupo a través de lo que no es, y los modelos cognitivos sobre la comprensión y las posturas acerca de las condiciones políticas y materiales e intereses que son conformados por una identidad particular (Lizama, 2013).

Las identidades determinan los intereses de los actores, dentro de los mismos procesos y sus normas en los que se definen las situaciones. Junto a ello, la formación de estructuras o conjuntos de identidades e intereses generan instituciones mediante la 
interiorización de nuevas identidades e intereses, ya sean cooperativas o conflictivas (Porcelli, 2013).

El rol de las normas también es relevante, al influir en las conductas, su propagación e internalización, y por su intersubjetividad. Según Katzenstein (1996), son "expectaciones colectivas sobre el comportamiento adecuado de los actores con una identidad determinada" (p. 5), pensadas como un concepto amplio, y que nacen con las creencias y los actos de los actores. Por eso son consideradas dinámicas y fluidas, aunque se reconoce que reflejan estabilidad, en el sentido de que son reconocibles por expectativas conjuntas que estructuran los comportamientos. Al mismo tiempo, para el constructivismo -en el origen de los hechos tal como los conocemos-, se encuentran en un extremo la estructura (el entorno, instituciones y significados que establecen el contexto de la acción internacional y que "obligan" al actor a actuar de tal forma) y, en el otro, el agente -agencia- (comportamiento autónomo y deliberado del actor), elementos que se constituyen mutuamente puesto que son constructos sociales dinámicos, modelados por variados factores históricos, políticos, culturales y sociales (Sánchez, 2012).

Dicho de otra forma, un agente es, o depende de, un ser humano que es capaz de escoger y de actuar sobre la base de esta escogencia en algún ambiente social. Los seres humanos, como agentes, pueden crear personas ficticias como el Estado y otorgarles agencia a estas, al autorizar a algún ser humano, como agente, a actuar por ellos. Las principales características de los agentes son la intencionalidad y el significado. En contraste, la estructura social se refiere a patrones recurrentes de comportamiento social $\mathrm{y}$, especialmente, a aquellos patrones que parecieran fijar límites a la agencia humana. La estructura, ya sea como patrones observables o principios subyacentes, está separada del agente, pero permanece motivando la acción social (Kubálková, 2001).

Es, precisamente, a partir de las identidades e intereses de los actores intervinientes donde se vislumbra el verdadero significado de la política exterior desplegada por la Concertación de Partidos por la Democracia en el período estudiado, determinado por el ambiente social, político y económico de la transición chilena y de los cambios globales que se producían en esos tiempos.

En cuanto al comportamiento estatal, este es afectado tanto por variables domésticas como internacionales, superando cualquier dicotomía entre la política interna y la externa (Ferguson y Mansbach, 1991). La primacía de una u otra dimensión dependerá de elementos como el contexto en que se desenvuelva o el área en que el Estado deba adoptar una decisión, así como de condiciones objetivo-racionales (obtención de ganancias) o subjetivo-ideacionales que responden a valores compartidos (Álvarez, 2015). En este contexto debemos comprender la política exterior como un proceso continuo de decisiones (Calvert, 1986) que los gobiernos elaboran en función de preferencias y problemas provenientes del exterior, así como de pautas y prácticas endógenas (Lasagna, 1995). Estos conceptos se traducen en objetivos, metas, estrategias $\mathrm{y}$ acciones, condicionados por elementos internos y foráneos, tanto formales como informales, procedentes de la cultura política o de la personalidad de la élite que toma 
las decisiones. Considerar la agencia y la estructura en mutua constitución refuerza lo que estamos diciendo (Klotz y Linch, 2007), puesto que ocurre que las instituciones se tensan para obligar al actor a proceder de una determinada forma, enfrentándose con el comportamiento autónomo y deliberado de ese mismo actor.

En el caso chileno, la profundidad y el ritmo de la reestructuración de la política exterior puede presentarse como un modelo híbrido, resultado de las interacciones entre la agencia y las estructuras nacionales y globales en que se producen algunas transformaciones fundamentales. Por entonces se hacía necesario superar el aislamiento internacional de la dictadura e insertarse en el mundo pos-Guerra Fría, a la vez que practicar reformas lentas y parciales, junto con propiciar pequeñas alteraciones que no implicaban realineamientos drásticos (Lasagna, 1995). Las tendencias más importantes originadas en el gobierno militar se mantuvieron, sostenidas por una derecha económica y políticamente poderosa, capaz de ejercer una suerte de veto, disponible en el entramado constitucional propio del proceso de transición (senadores designados, inamovilidad de los comandantes en jefe de las Fuerzas Armadas, altos quórums para cambiar la Constitución y el sistema binominal, entre otros instrumentos que le aseguraban poder a pesar de ser minoría).

Según Volgy y Schwarz (1991), la política exterior tiende a la continuidad, mientras no sea alterada por trastornos relevantes originados en el escenario global, al interior del Estado o en la sociedad. Aparte de los elementos ya citados, la estabilidad en el aparato estatal se apoya en las organizaciones burocráticas (Hermann, 1990), las cuales reciben la influencia de los partidos políticos que actúan en el sistema, de los grupos de interés y de los grupos de presión, los que constituyen "estabilizadores administrativos" (Goldmann, 1982).

A partir de la transición, Chile se proyectó al mundo con el objeto de participar activamente en la globalización. Esto se gestó mediante un esfuerzo de liberalización comercial, tanto unilateral como bilateral y multilateral, así como a través de la normalización de los vínculos diplomáticos con todas las naciones, asegurando su presencia en los foros internacionales y fortaleciendo las relaciones con el entorno vecinal; todo ello en la medida en que tales objetivos fueran compatibles con la escena política interna, sus condiciones y equilibrios.

Los supuestos del neoliberalismo, es decir, la ideología del Estado mínimo, la desregulación, la privatización y la reducción de los impuestos, entre otros, consiguieron ser hegemónicos luego de la caída de la Unión Soviética y de los procesos de creciente interdependencia económica en el sistema capitalista mundial, propiciando una forma de cooperación internacional basada en la apertura irrestricta de los mercados nacionales que, para las élites chilenas, era factible y provechosa (Keohane, 2001), debido a las transformaciones realizadas por el gobierno militar a partir de 1975. Así se consolidó durante la transición un consenso, vigilado por la amenaza restauradora del antiguo dictador que ocupaba la comandancia en jefe del Ejército, por las leyes de amarre, por la gran debilidad del movimiento sindical, por la hegemonía del pensamiento neoliberal y por la debilidad de la izquierda. Esa era la correlación de 
fuerzas sobre la que se estructuró el consenso de la transición (Rivera, 7 de mayo de 2014).

Los factores propios de los regímenes democráticos explicarían el comportamiento estatal cooperativo, junto con las características nacionales que influyen en los grupos e individuos que participan en la definición de políticas, además de articular coaliciones y redes con sus contrapartes foráneas para incidir en los procesos externos (Keohane y Nye, 1988). La práctica chilena indica que los componentes determinantes de la transición estaban convencidos de que la democracia era el único camino posible, aunque con las restricciones que ellos mismos habían incluido en la Constitución de 1980.

Por su parte, los elementos internos adquieren mayor importancia para entender los procesos exógenos, puesto que existen convergencias o divergencias relativas a ideas que influyen en los intereses y en las relaciones entre los Estados, y entre los actores domésticos que participan en la construcción de las políticas exteriores (Hopf, 1998; Wendt, 1995), tales como el relacionamiento formal a través de un conjunto de normas, e informal, mediante la socialización mutua (Álvarez, 2015). Sobre estas condiciones se despliegan líneas de acción cuyo significado equívoco nos permite llamarlas zombis, al tiempo que ese mismo talante facilita explicar al conjunto de la política exterior de Chile en el período histórico que trata este artículo.

El desarrollo de un punto de vista como el señalado nos lleva a afirmar que los conceptos política exterior de Estado, prioridad latinoamericana y regionalismo abierto son ideas que se construyen en la acción, conformando narrativas que convienen a los actores internos más fuertes o hegemónicos involucrados, apartándose de definiciones generales, atemporales o simplemente dadas.

La hipótesis planteada será comprobada mediante el análisis crítico de la bibliografía citada y su contraste con entrevistas a actores importantes en la toma de decisiones de la época en estudio, exponiendo los argumentos por secciones, tituladas según cada una de las categorías que hemos considerado zombis en el marco teórico antes revelado. Finalmente, concluiremos con una reflexión acerca de si los elementos presentados en este estudio han sido demostrados tal como nos propusimos.

\section{Política de Estado}

En Chile, la política exterior se ha considerado una política de Estado, es decir, una política de largo plazo que responde a los intereses generales de la sociedad y que, por tanto, goza de consenso suprapartidario (Bachelet cit. en Cook, 2012). Sin embargo, aparte del plano limítrofe, sobre todo cuando hubo conflictos con los vecinos, no se trata del producto de un acuerdo, sino de la obligación de converger con la posición oficial, originada por factores como la visión hegemónica de la transición, el temor al fracaso de la democracia recién conquistada, y el entramado de vetos, frenos y contrapesos institucionales de la transición, posición que es liderada por el Presidente de 
la República al ser el protagonista principal de la toma de decisiones en esta materia. Un ejemplo de ello es el caso de las relaciones con Cuba, limitadas al comienzo al plano consular y que solo luego de un largo período alcanzó un nivel diplomático normal.

Este supuesto consenso no requiere la ratificación de la sociedad, sino que se conforma con la ausencia, poca articulación o debilidad de un punto de vista opositor. Se trata de un consenso pasivo, cuando no negativo, que evita abordar determinadas cuestiones (Del Arenal, 2008). Asimismo, es contrario a la búsqueda activa de coincidencias en torno a algunos valores y principios que sustenten la política exterior de un Estado, por lo que se construye sobre la simple hegemonía de grupos, instituciones y estructuras.

La teoría realista clásica que funciona como base para explicar y justificar esta conducta, entiende la política exterior como expresión del núcleo central de los intereses de la comunidad organizada, alrededor de la cual los partidos no pueden hacer otra cosa que elaborar consensos profundos y de largo plazo. Vale la pena preguntarse, en congruencia con el constructivismo, quién identifica, interpreta y prioriza el interés nacional, o cómo se hace, o cuándo, o por qué.

Según el ethos realista, el fin primordial de la acción del Estado sería la defensa del interés nacional, traducido como la acumulación de poder para defenderse y prevalecer, sin que sean aceptables posiciones distintas ni otras identidades o sectores minoritarios. No obstante, el análisis constructivista visualiza la escena externa de una manera mucho más compleja, mezclando ideas, sujetos y entidades de variada índole, sin que nadie posea soberanía completa o influencia suficiente para alcanzar todos sus fines. Además, la guerra está cada día más limitada, y el derecho y los vínculos pacíficos predominan en amplios aspectos de la vida internacional. Esto no significa que la fuerza, el conflicto y el poder hayan dejado de ser elementos relevantes, pero ya no son insustituibles o categóricos, y el resultado de su construcción es siempre compleja.

Esta forma de hacer las cosas se contradice con la vida democrática contemporánea, sujeta al cambio permanente y al libre juego de mayorías y minorías, aunque se reconozca que es mejor fijar ciertos criterios comunes sobre los asuntos más importantes de la agenda internacional, lo cual, por cierto, continúa siendo opcional.

Las políticas exteriores se han politizado en la era de la globalización y han pasado a ser materia del debate interno, descartando consensos de largo plazo, salvo en aquellas situaciones que ameritan reconocer un puñado de asuntos esenciales o líneas maestras, susceptibles de sustraerse de la cotidianidad democrática (Del Arenal, 2008). Más bien, las políticas exteriores contemporáneas reconocen que el desafío es gestionar el disenso para evitar divisiones que puedan afectar la eficacia de la acción internacional del Estado.

El interés nacional ha sido reemplazado por los intereses de los ciudadanos, definidos en una sociedad democrática tras una adecuada deliberación (Nye, 2002), los cuales se orientan mediante acuerdos mínimos compatibles con las condiciones actuales, por completo distintos al antiguo Estado-centrismo en las relaciones internacionales. Debiéramos agregar a los lobbies de todo tipo que intentan orientar las preferencias 
estatales y que, tampoco, pueden ser confundidos con una suerte de interés llevado a un plano casi metafísico.

A pesar de las transformaciones globales, la tradición continúa en los sectores más conservadores y en los países periféricos, donde se mantiene como la doctrina práctica del aparato público, más aún cuando la tendencia de procesos de transición a la democracia similares al chileno ha sido el protagonismo de las organizaciones burocráticas estatales de mayor relevancia y de los grupos de presión privados más importantes (Colombo, 2010).

Tal como afirman los enfoques internacionales contemporáneos, entre ellos el constructivismo, es necesario analizar el Estado en función de cómo y quién toma las decisiones en su nombre. Para hacer eso en Chile es esencial analizar la transición a la democracia, cuyas reglas dirigían el sistema político nacional.

La política exterior chilena expresó los acuerdos entre los poderes existentes en la sociedad, dentro de un marco constitucional donde la función del Ejecutivo más que sustantiva es privativa (Constitución Política de la República de Chile, Artículo 32, $\mathrm{N}^{\circ}$ 15, 1980). El jefe del Estado ha sido el representante de la unidad de la nación, la más importante autoridad en la toma decisiones acerca de las relaciones internacionales, frente a un Congreso muy disminuido, así como el principal baluarte democrático frente a las instituciones conservadoras y neoliberales no elegidas que establece la Carta Fundamental de 1980.

Entre los grupos intervinientes en el proceso de toma de decisiones que podemos identificar como fuentes internas de la política exterior, encontramos a los segmentos burocráticos estatales ya mencionados (tradición diplomática y funcionarios del servicio exterior que defienden sus demandas corporativas), además de las Fuerzas Armadas a través de la doctrina estratégica que, al decir de Ángel Flisfisch (comunicación personal, 24 de julio, 2013), resguarda el statu quo en las fronteras, y los empresarios cuyos intereses se encuentran representados por los principios e instituciones del modelo económico. Esto debe complementarse con la élite política analizada en capítulos anteriores.

En este segmento es interesante anotar que a mediados de la década de 1990 las asociaciones empresariales empezaron a distanciarse de los partidos de oposición y a mostrar un mayor grado de compromiso con la acción gubernamental. En el caso concreto del Acuerdo de Complementación Económica (ACE) con el Mercado Común del Sur (MERCOSUR), solo los representantes de la Confederación de la Producción y el Comercio (CPC), más la oposición, subrayarían la escasa incidencia del acuerdo en términos de liberalización comercial, insistiendo en la vía unilateral. Otra era la opinión de la Sociedad de Fomento Fabril (SOFOFA) y la Asociación de Exportadores de Manufactura (ASEXMA).

Según Wilhelmy (2015), tal situación se enmarca en un contexto en el cual "la influencia del sector privado en los procesos de la política exterior es significativa, especialmente en los asuntos económicos internacionales que constituyen el área 
prioritaria de interés del empresariado chileno dentro de la agenda externa del país" (2015: 57). Por otra parte, los acuerdos sometidos a la ratificación del Congreso implicaron la aceptación - por parte del Ejecutivo- de ciertas iniciativas del Legislativo en la política exterior, relacionadas básicamente con el apoyo de gestiones internacionales directas en temas económicos y políticos, actividades denominadas diplomacia parlamentaria (Cook, 2012). De todos modos, aquellas acciones no constituyeron prerrogativas distintas a las que indica expresamente el marco constitucional. El Presidente expresa un consenso, devenido en automático, frente al cual partidos políticos débiles y que no tienen los temas internacionales entre sus prioridades, junto a una ciudadanía poco informada, se reducen a asentir sin mayores críticas. La figura presidencial se convierte en el supremo representante del Estado, posición que coincide con la definición realista en cuanto a su facultad exclusiva para interpretar el interés nacional.

En atención a lo anterior, la política de Estado adquiere contornos confusos, pues funciona como mínimo común denominador al concordar con el establishment conservador, pero se difumina cuando se aleja de esos principios, dejando fuera a aquella parte de la sociedad que disiente del consenso hegemónico.

\section{El regionalismo abierto}

El concepto de regionalismo abierto dominó la política exterior chilena desde la segunda parte de la década de 1990 hasta el 2011, fecha en la cual pasó a formar parte como miembro pleno de la Alianza del Pacífico, agrupación regional que pretende alcanzar una integración profunda, pero que mantiene inalterada la idea de apertura no discriminatoria, pues Chile trata por igual al conjunto de las economías mundiales con las que tiene algún acuerdo. A pesar del discurso, la inserción internacional del país se basó en las relaciones con sus principales socios comerciales, sin priorizar ninguna región (Fuentes, 2012).

Tampoco la participación en calidad de asociado en el MERCOSUR, o en la CELAC (Comunidad de Estados Latinoamericanos y Caribeños), o en los mecanismos de concertación dispuestos por la UNASUR (Unión de Naciones Suramericanas), son prueba de una preferencia real por América Latina, ya que corresponden a instancias de contenido más político, área donde Chile se abstuvo de pasar más allá del diálogo y la concertación, estableciendo diferencias claras de estrategia económica que impidieron una integración más rotunda.

La intensidad en los intercambios y la cooperación obtenida con algunos países del entorno más próximo, tales como Argentina, Perú, Colombia y Brasil, no alcanzan para justificar alguna forma de regionalismo, puesto que se conservan en el ámbito bilateral, independientes de las estructuras a las que pertenecen.

¿De dónde surge esta realidad? El entramado político-económico de la transición determinó que los gobiernos democráticos continuaran con la apertura unilateral 
establecida por el régimen militar, pero complementándola con una participación activa en las negociaciones multilaterales y con la suscripción de pactos bilaterales como los ACE y los Tratados de Libre Comercio (TLC). En ese contexto, la economía chilena logró insertarse en el área del Asia Pacífico, principal motor del sistema capitalista mundial. En 1989 se había creado el APEC (Asia-Pacific Economic Cooperation), estructura guiada por el principio del regionalismo abierto, entendido como alternativa a los bloques económicos, basado en los consensos no vinculantes (CEPAL, 2001). Esta noción tuvo su origen en la propuesta del Primer Ministro de Japón, Masayoshi Ohira (Palacios, 1995), quien la presentó como la idea de una región abierta, integrada por los países asiáticos y de la Cuenca del Pacífico (CEPAL, 2001).

En democracia, la presencia chilena en esta región se transformó en el más importante de los ejes de una política exterior que había sido definida por el presidente Eduardo Frei Ruiz-Tagle (1994-2000) como una herramienta para el desarrollo nacional, condición vinculada al crecimiento de inversiones y exportaciones (Frei Ruiz-Tagle, 1999). Si a esto agregamos que la política exterior debe ser una política de Estado, queda clara la continuidad de una proyección internacional cuya centralidad estratégica coincide con objetivos propios del neoliberalismo; vale decir, la despolitización, la reducción al mínimo de la intervención estatal, la privatización de la economía, la desregulación de los mercados y la libertad de comercio (Meyer, 1995).

Sin embargo, la adhesión al regionalismo abierto soslayó una definición más precisa del concepto, puesto que puede ser interpretado según el modo asiático como aperturas económicas unilaterales y concertadas, sin reciprocidad, aunque con intensas corrientes de cooperación (Yamazawa, 21 de diciembre de 1994); o, como indica la CEPAL (2001), a partir de la suscripción de acuerdos regionales que contemplen mecanismos para favorecer el libre comercio y competir mejor en los mercados mundiales.

Según algunos autores como Van Klaveren (1998) y Bernal-Meza (2001, 2005), las distintas opciones de inserción internacional no serían excluyentes, sino que tenderían a complementarse, afirmación que, a nuestro juicio, es controvertible, pues si bien ambas parten de la base de una necesaria participación en la globalización, unas privilegian el ámbito nacional y regional, y otras, los mercados mundiales. Es así como, entre 1990 y 2010, se aplicó en Chile una versión del regionalismo abierto que impedía ingresar como miembro pleno al MERCOSUR, ya que restringía la autonomía del país para convenir programas de liberalización comercial con otras naciones, y el arancel externo común del bloque era más alto y escalonado que el chileno (entre $2 \%$ y $20 \%$, menos algunas excepciones), contraviniendo nuestra política de aranceles bajos y parejos. Esta decisión fue consecuente con la preferencia por una asociación bajo la lógica bilateral, sin que necesariamente las partes tuvieran identidad geográfica, reservando la carta multilateral solo cuando se tratase de regímenes abiertos. No ha existido en la política exterior de Chile compromiso alguno que ate al país a obligaciones preferenciales exclusivas con sus vecinos, sino que, como puede verificarse, ha propiciado un trato igualitario con el resto del mundo, ya sea a través de instrumentos bilaterales o en el contexto de las negociaciones de la Organización Mundial del Comercio (OMC). 
Es legítimo, por tanto, preguntarse cuánto de regional tiene la definición de regionalismo que usó Chile, sobre todo si el gobierno del presidente Eduardo Frei RuizTagle estableció la necesidad de una inserción múltiple en la economía global, implementada mediante la suscripción de tratados con nuestros principales socios comerciales (Fuentes, 2012). La constatación de que en la práctica del comercio internacional de Chile existía un equilibrio en los intercambios con Europa, Estados Unidos y el Asia, se apreció como una ventaja, pues al no depender de una sola economía se evitaba el contagio de posibles crisis de origen único, aunque se obviaron vulnerabilidades propias de una apertura tan extensa. Además, el cuarto socio, Latinoamérica, quedó en un lugar más bien alejado del protagonismo que ocupaban las grandes potencias compradoras de exportaciones con poco valor agregado, sin tomar en cuenta que la región era el principal importador de las manufacturas chilenas.

En síntesis, el regionalismo abierto practicado por Chile no es una tercera versión del término, sino que se trató de una traducción particular de la liberalización comercial, abierta a todas las regiones del mundo, aunque con algunas particularidades lógicas en los ámbitos de mayor proximidad geográfica, concernientes a acuerdos económicos, a la superación de ciertas controversias limítrofes, ${ }^{2}$ a las inversiones y a la facilitación fronteriza (Fuentes, 2012).

Ninguna de estas experiencias logró superar aquello que la ALADI (Asociación Latinoamericana de Integración) llamó "bilateralismos convergentes", concepto que podemos interpretar como un marco bilateral o plurilateral a partir del cual los países pueden pactar acuerdos con terceras partes, sin que exista la obligación de actuar en conjunto o siquiera de multilateralizar preferencias, puesto que ni se cuenta ni se requiere de un proyecto de integración más completo (Casanueva, 18 de diciembre de 2007). Por cierto, lo que hizo la ALADI para concertar voluntades en torno al esfuerzo integracionista, utilizando una mayor flexibilidad y pragmatismo, se convirtió en otra cosa al alejar las metas más ambiciosas y condicionar el avance del proceso al éxito de los negocios.

\section{Prioridad latinoamericana}

La relación de Chile con su región ha sido un tema controvertido y contradictorio en la política exterior del país desde el regreso a la democracia en 1990. Al comienzo tuvo relevancia política y económica, en el contexto de la crisis de la deuda externa de los

\footnotetext{
2 Durante los años noventa fueron resueltas todas las controversias limítrofes con Argentina, con excepción de la porción norte de Campos de Hielo Sur, aunque existe un itinerario claro de solución. Chile dio cumplimiento a las cláusulas pendientes del Tratado de 1929 con Perú, pero más tarde Lima decidió llevar a la Corte Internacional de Justicia de La Haya (CIJ) su pretensión de redefinir el límite marítimo con Chile. En cambio, con Bolivia persiste el tema de una salida soberana al océano Pacífico por territorio chileno, incluso a pesar de la sentencia de la CIJ (2018), que declaró que no existe una obligación de negociar una salida soberana al mar por parte de Chile.
} 
años ochenta y de la búsqueda de la paz en América Central, aunque la prioridad del gobierno de Patricio Aylwin (1990-1994) fue la reinserción internacional en su más amplio concepto (Rojas, 1997), después de 17 años de una dictadura civil-militar aislada políticamente del resto del mundo (Portales, 2011).

En concreto, los esfuerzos de la primera administración de la Concertación de Partidos por la Democracia se concentraron en formalizar los primeros ACE y en dar solución a los problemas pendientes con los vecinos, sobre todo con una Argentina que coincidía no solo con el espíritu integracionista, sino que con un modelo económico muy parecido. No obstante, a pesar de algunos avances importantes -como la ejecución de las cláusulas pendientes del Tratado de 1929 con Perú y la firma de un ACE asimétrico que reconoció las diferencias entre ambas economías y dio preferencias especiales a Bolivia- prevaleció la agenda histórica derivada de la Guerra del Pacífico (1879-1883), que en este caso refiere a la mediterraneidad del país altiplánico.

Profundizando en lo que ya dijimos más arriba, los factores que explicarían la estrategia con que los gobiernos de la transición democrática continuaron la apertura comercial de Chile serían: a) el tamaño reducido del mercado y de la dotación de factores productivos; b) el objetivo de reinsertarse en el escenario de las naciones democráticas; c) las profundas transformaciones globales de la década de 1990, que reafirman la vigencia del capitalismo como único modelo viable; y d) la necesidad de consolidar la transición y garantizar una cierta perspectiva de crecimiento, para lo cual América Latina no era suficiente, pues nuestros principales mercados no estaban allí, junto con la no existencia de un motor regional capaz de arrastrar al resto de las economías (Furche, comunicación personal, 27 de septiembre, 2013).

Aparte de una lógica esencialmente pragmática como el punto de vista oficial citado en el párrafo precedente, el triunfo de una tendencia más proclive a las relaciones con socios extrarregionales se explica también en las palabras de Augusto Aninat (comunicación personal, 10 de julio, 2013), primer Director de Relaciones Económicas Internacionales (DIRECON) del gobierno de Patricio Aylwin, quien explicita su preferencia por "un club de países pequeños, democráticos, de economías de mercado, con inquietudes sociales, unos demócratas de centro izquierda". De igual manera, firmar un pacto con Estados Unidos (primero bajo el formato TLCAN [Tratado de Libre Comercio de América del Norte] y luego como un tratado bilateral de libre comercio) significaría anclar definitivamente el modelo económico (Bermúdez, comunicación personal, 23 de julio, 2013), criterios que terminaron por establecer un nivel de menor importancia real a las relaciones con América Latina, a pesar de que esta zona siguió siendo declarada como prioridad de la política exterior por todos los gobiernos de la transición.

Para Roberto Pizarro (comunicación personal, 16 de septiembre, 2013), exministro de Planificación y Cooperación en el gobierno de Frei, el complemento bilateral de la apertura económica unilateral vigente antes del gobierno de Patricio Aylwin tenía como camino natural a América Latina, ya que coincidía con la experiencia de los miembros 
del equipo que trabajaban en el tema y con los instrumentos disponibles, en este caso, los ACE, en el marco de la ALADI.

Para otros como Aninat (comunicación personal, 10 de julio, 2013), al fracasar la idea de juntarse con los suecos, con los noruegos, los holandeses y los belgas, la respuesta más simple y directa era la región. Por una razón u otra, durante los primeros dos años el énfasis lógico se puso en Latinoamérica (1990-1992). En la misma ocasión, Pizarro cuenta que:

Por problemas de institucionalidad interna, por la preocupación de la Concertación en torno a mantener lo que habían sido los equilibrios macroeconómicos de la dictadura y por concepciones distintas de negociaciones de la apertura, el Ministerio de Hacienda comienza a jugar un rol trascendente también en las negociaciones internacionales, dividiéndose el mundo en el norte (a cargo de Hacienda) y el sur (para el Ministerio de Economía y la DIRECON). (Comunicación personal, 16 de septiembre, 2013)

Pizarro continúa:

A fines de 1990 se da otro fenómeno, ya que George Bush padre (presidente de Estados Unidos) lanza la Iniciativa para las Américas, propuesta que recoge el ministro de Hacienda Alejandro Foxley y que lo incentiva a viajar a Washington. Entre 1990 y 1992 hay un conflicto cerrado y a veces abierto con los funcionarios de Hacienda, que son los encargados de las negociaciones. Ellos siempre se muestran molestos con las negociaciones que hacíamos con América Latina, intentando bloquearlas, boicotearlas, poniendo trabas y dificultades, pues esto no le interesaba al país. Allí es donde el ministro Alejandro Foxley nos bautiza como "los últimos latinoides" (haciendo un símil con la calificación de humanoides con que el Almirante José Toribio Merino, miembro de la Junta de Gobierno de la dictadura chilena, se refería a los comunistas). De cualquier modo, las negociaciones al final seguían marchando inevitablemente, hasta que eligen de presidente a Bill Clinton, en noviembre de 1992. (Comunicación personal, 16 de septiembre, 2013)

Y agrega:

Nosotros ya habíamos cerrado negociaciones con México, en el marco del acuerdo de complementación de la ALADI. También habíamos hecho con Argentina un acuerdo, antes de lo que fue la negociación con el MERCOSUR; estaba en proceso el acuerdo con Venezuela, pero Foxley conversa con cada uno de los miembros del Comité de Negociaciones Económicas Internacionales (ministros de Hacienda, Agricultura, Economía, Relaciones Exteriores, el Secretario de la Presidencia y la DIRECON), y afirma que se dan las condiciones para incorporarse al NAFTA, o para tener un Acuerdo de Libre Comercio con Estados Unidos, lo cual le cambiaría el pelo a Chile y significaría entrar definitivamente en la modernidad. Foxley afirmaba que seguir con América Latina sería una deslealtad para Estados Unidos, porque los países entrarían por la vía de Chile a este compromiso de libre comercio. El ex canciller Enrique Silva Cimma dijo que eso no podía ser, pues en unos días se firmaba un acuerdo con Venezuela, por lo que era una deslealtad con el 
presidente Carlos Andrés Pérez, aunque a Foxley eso no le interesaba. Más aún, el ministro de Hacienda afirmó que en seis meses él conseguía un Acuerdo de Libre Comercio con Estados Unidos, aunque no había fast track (permiso de vía rápida del Congreso norteamericano), ni el acuerdo necesario con las instituciones involucradas en los procesos negociadores. (Comunicación personal, 16 de septiembre, 2013).

En esta misma comunicación personal, Pizarro consigna que el tiempo que se demoró en concretar el Tratado de Libre Comercio con Washington no impidió que se internalizara el concepto de que debía preferirse a Estados Unidos, en paralelo a las conversaciones con Europa, por lo que la prioridad latinoamericana empezó a diluirse.

Dando un salto en el tiempo, Pizarro afirma que en agosto de 2000 el presidente Ricardo Lagos intentó incorporar a Chile de manera plena en el MERCOSUR, al cambiar el estatus de asociado alcanzado durante la administración del presidente Eduardo Frei Ruiz-Tagle. Sin embargo, después de tres o cuatro rondas de negociación todo esto terminó, porque, según Pizarro:

En alguna reunión internacional, el presidente Clinton le habría dicho a Lagos que estaban maduras las condiciones para avanzar en el acuerdo de libre comercio. Y ahí el gobierno norteamericano inicia las negociaciones con Chile, pero no ponía como condición evitar los compromisos con América Latina; eso fue una cosa que se le ocurrió a Foxley. (Comunicación personal, 16 de septiembre, 2013)

Esta conducta ha sido catalogada como pragmática, relacionada con el desarrollo del comercio y de las exportaciones de los productos más importantes de Chile, de la inserción del país en la globalización. No obstante, de acuerdo con el testimonio de Alberto Van Klaveren, exasesor, embajador y subsecretario del Ministerio de Relaciones Exteriores:

Yo participé muy activamente en toda la discusión que hubo inicialmente relativa al TLC con Estados Unidos, la cual era una posición absolutamente consensual dentro del Gobierno de Aylwin, existiendo algunas diferencias más bien en cómo hacerlo, cómo lograrlo. Se formó un grupo informal, en el que participaba Edgardo Böeninger (ministro secretario general de la Presidencia), Alejandro Foxley y Enrique Correa (ministro secretario general de Gobierno), y por la Cancillería no participaba Enrique Silva Cimma, porque se consideraba que él no era un firme partidario del acuerdo con Estados Unidos, así que lo reemplazaba Carlos Portales (director general de Política Exterior del Ministerio de Relaciones Exteriores) como enlace con el Ministerio. A mí me tocó, justamente por mi relación de amistad con Carlos, participar varias veces en ese grupo, a pesar de que no tenía ningún cargo oficial. Ahí me quedó muy claro que en la percepción de este grupo la negociación con Estados Unidos era clave para anclar el modelo económico, es decir, no interesaba tanto el tema del libre comercio, tampoco interesaba tener mayor inversión norteamericana, todo eso era obviamente muy bienvenido. El tema clave en la percepción de los actores de esa época era anclar el modelo. Esa era la concepción especialmente 
de Alejandro Foxley y Edgardo Böeninger. (Van Klaveren, comunicación personal, 17 de junio, 2013).

En el mismo sentido, Pizarro puntualiza que:

La política internacional no es sino reproducción, o proyección de la política nacional, pues si la política nacional viene siendo desde hace 40 años de libre mercado interno, no tiene por qué no ser de libre mercado internacional. En una política pragmática había que buscar maneras de que no se nos fuera toda la industria, pero de eso no hay nada, ni un pequeño énfasis que favoreciera a los pequeños productores industriales, entonces, al final lo que sucede con esta apertura económica al mundo, cuando se abre todo y no se hacen matices en la protección al sector financiero, lo que resulta es reafirmar que este es un país destinado a exportar y producir recursos naturales. (Comunicación personal, 16 de septiembre, 2013).

La relevancia de la apertura económica para la política exterior, el carácter no regional de los acuerdos comerciales, la preferencia por los socios del mundo desarrollado que compran las materias primas chilenas (commodities) y cierto desdén por las opciones integradoras de la región, vistas más como vulnerabilidades y amenazas que como una potencialidad a desplegar, incluso para una industria no fundada en la protección estatal, hicieron que las declaraciones gubernamentales acerca de la prioridad latinoamericana se quedaran solo en el discurso oficial.

Más allá de reconocer que Chile debía hablar desde su entorno para ser escuchado en el escenario internacional, el país participaba en espacios de integración que no pasaban de ser un ejercicio de concertación política a nivel general. Asimismo, el acercamiento a los vecinos era relevante por sus múltiples implicancias, pero era escasa la concreción de acuerdos que transitaran de la cooperación a la asociación, como sucede en las relaciones que se suponen más avanzadas con Argentina. Todo ello hacía parecer que el norte estaba puesto en otra parte.

Ese objetivo siguió siendo el que fijó el proceso de transición a la democracia, es decir, acceder de manera segura a la mayor cantidad de mercados del planeta, vincularse preferentemente con Estados Unidos - en cuanto era la principal potencia del mundo y el poder hegemónico en la región- y con aquellas naciones que compartían una visión que entiende a Chile como un país de ingresos medios, democrático y de economía abierta. Lejos quedó, por cierto, una América Latina sometida a los vaivenes de la política, inestable por naturaleza y propensa a caer en los populismos de izquierda, prevaleciendo la idea, como nos dice el exministro de Economía y senador de la República, Carlos Ominami, de que "Chile es una buena casa en un mal vecindario" (Ominami cit. en Vargas, 22 de enero de 2014, s. p.).

Incluso en la política vecinal, donde resaltan con claridad los avances producidos en el período de gobierno del Presidente Patricio Aylwin (1990-1994), se produjo en los años siguientes una situación marcada por la continuidad, prevaleciendo el statu quo, favorable a Argentina y conflictivo con Perú y Bolivia. 


\section{Conclusión}

La exploración llevada a cabo en este artículo nos ha llevado a comprobar que en la política exterior chilena de la transición (1990-2010) existen conceptos como el regionalismo abierto, la prioridad latinoamericana y la política de Estado, que adquieren el carácter de categorías zombis, pues su significado práctico se aleja de su sentido original en algunas fases del proceso.

Desde el constructivismo, utilizado como marco teórico, podemos observar que la interrelación entre agencia y estructura explica la construcción social de conceptos que tienen un nombre, pero implican otra cosa. Ello sucede siguiendo la lógica transicional del período, en el que ante las distintas visiones en juego sobre la proyección internacional del país se imponen las preferencias de los actores más relevantes de la política interna. Entonces, si nuestra política exterior se manejó alrededor de criterios zombis, sería posible concluir que nos encontramos ante una especie de política vudú, ya que es digitada a partir de intereses que no se mostraban abiertamente y sin debates exhaustivos que concernieran a las instituciones de la democracia, debido a que las contradicciones existentes en el seno de la coalición gobernante y el peso de la oposición de derecha daban mayor viabilidad a un aparente acuerdo legitimador, bajo el nombre de "política de Estado".

El resultado de dicha situación, por ende, no podía ser distinto al dominio del statu quo en la toma de decisiones, que impedía innovar si el escenario internacional cambiaba, tal como sucedió a menudo en estos años de post-Guerra Fría. Ante una incierta realidad global y un difícil equilibrio de fuerzas en el escenario doméstico prevaleció una cierta manera de ver las cosas - calificada como correcta y que disciplina el discurso-, una versión del lenguaje que manda y obliga. Aquello sería la raíz de la creación zombi, la doctrina vudú que justificó el uso de nociones formalmente contradictorias con el conservadurismo, pero consecuentes con sus aplicaciones prácticas, en el marco de la estabilidad que aparecía como objetivo primordial de la transición.

Esto se selló con una suerte de acuerdo político tácito o implícito entre agentes tales como una derecha globalizadora en lo económico y nacionalista en lo político, y la centro-izquierda que gobernó durante los veinte años de la transición, consistente en respetar la cáscara progresista de los conceptos a condición de aportar la sustancia, sobre todo si la coincidencia real giraba alrededor de la apertura económica al mundo. Dicho de otro modo, la agencia y la estructura se constituyen mutuamente mediante la práctica de los agentes sociales en esta fase histórica de la transición chilena (Klotz y Lynch, 2007; Price y Reus-Smit, 1998).

\section{Referencias bibliográficas}

Adler, E. (2010). Damned if you do, damned if you don't: 'Performative power', and the strategy of conventional and nuclear defusing. Security Studies, 19(2), 199-229. 
Recuperado

de

https://www.tandfonline.com/doi/abs/10.1080/096364 11003796002

Adler, E. (2013). Constructivism in International Relations: Sources, contributions, and debates. En Autor, Handbook of International Relations (pp. 112-144). Londres: Sage Publications Ltd.

Álvarez, G. (2015). Hacia una perspectiva constructivista y crítica del análisis de política exterior. Revista de Estudios Internacionales de la Universidad de Chile, 47(180), 47-65.

Arriola, J. (2013). El constructivismo: su revolución onto-epistemológica en Relaciones Internacionales. Revista Opinião Filosófica, Porto Alegre, 4(1), 377-396.

Barkin, S. (2010). Realist Constructivism: Rethinking International Relations Theory. Cambridge: Cambridge University Press.

Beck, U. (2004). Poder y contrapoder en la era global. La nueva economía política mundial. Barcelona: Paidós.

Bernal-Meza, R. (2001). El regionalismo: concepto, paradigmas y procesos en el sistema mundial contemporáneo. En L. Bizzozero e I. Clemente (coords.), La política internacional en un mundo en mutación (pp. 11-30). Montevideo: Ediciones de la Banda Oriental.

Bernal-Meza, R. (2005). América Latina en el mundo. El pensamiento latinoamericano y la teoría de las relaciones internacionales. Buenos Aires: Nuevo Hacer.

Calvert, P. (1986). The Foreign Policy of New States. Londres: Wheatsheaf Books.

Casanueva, H. (18 de diciembre de 2007), Para salvar la integración latinoamericana. El Mostrador, s. p. [En línea]. Recuperado de http://www.elmostrador.cl/ noticias/opinion/2007/12/18/para-salvar-la-integración-latinoamericana/

Constitución Política de la República de Chile [Const.]. Decreto 100. Fija el texto refundido, coordinado y sistematizado de la Constitución Política de la República de Chile. 17 de septiembre de 2005 (Chile). Recuperado de https://www.bcn.cl/leychile/navegar?idNorma=242302\&idParte $=$

Cook, O. (2012). El Congreso Nacional en la política exterior de Chile, marzo 1990marzo 2010. En M. Artaza y C. Ross (eds.), La politica exterior de Chile, 19902009: del aislamiento a la integración global. Vol. 1 (pp. 239-262). Santiago: Ril Editores.

Colombo, S. (julio, 2010). La política exterior y los principales sectores de poder económico de Argentina durante el gobierno de Cristina Fernández de Kirchner. Ponencia presentada en el V Congreso Latinoamericano de Ciencia Política, Buenos Aires, Asociación Latinoamericana de Ciencia Política. 
CEPAL (marzo, 2001). Regionalismo abierto: un examen del concepto a la luz de las experiencias de América Latina y Asia y el Pacífico, 1999-2000. Panorama de la inserción internacional de América Latina y el Caribe, Capítulo VII. Santiago: CEPAL. Recuperado de https://www.cepal.org/sites/default/files/ publication/files/1191/S2001998_es.pdf

Del Arenal, C. (2008). Consenso y disenso en la política exterior de España. Real Instituto Elcano, Documento de Trabajo $\mathrm{N}^{\circ} 25$. Recuperado de http://www.realinstitutoelcano.org/wps/wcm/connect/15c494004f019704a004e4 3170baead1/DT25-2008_Arenal_politica_exterior_consenso.pdf?MOD=AJPE RES\&CACHEID=15c494004f019704a004e43170baead1

DIRECON (2009). Chile: 20 años de negociaciones comerciales. Santiago: Subsecretaría de Relaciones Internacionales.

Ferguson, Y. H. y Mansbach, R. W. (1991). Between celebration and despair: constructive suggestions for future international theory. International Studies Quarterly, 35(4), 363-386.

Frei Ruiz-Tagle, Eduardo (1999). Mensaje presidencial. Sesión del Congreso pleno, 21 de mayo. Historia política legislativa del Congreso nacional de Chile. [En línea]. Recuperado de https://obtienearchivo.bcn.cl/obtienearchivo?id= recursoslegales/10221.3/10559/6/19990521.pdf

Fuentes, C. (2012). El regionalismo abierto en la política exterior chilena, ¿versión original o concepto equívoco? Revista Enfoques, Universidad Central de Chile, 10(17), 19-31.

Garretón, M. A. (2012). Neoliberalismo corregido y progresismo limitado. Los gobiernos de la Concertación en Chile, 1990-2010. Santiago: Editorial ARCISCLACSO-PROSPAL.

Goldmann, K. (1982). Change and stability in Foreign Policy: Detente as a problem of stabilization. World Politics, 34, 422-440.

Hermann, Ch. H. (1990). Changing course: When goverments choose to redirect Foreign Policy. International Studies Quarterly, 34, 3-21.

Hopf, T. (1998). The promise of constructivism in International Relations Theory. International Security, 23(1), 171-200.

Katzenstein, P. (1996). The Culture of National Security. Norms and Identity in World Politics. Nueva York: Columbia University Press.

Joignant, A. y Güell, P. (eds.) (2011). Notables, tecnócratas y mandarines: Elementos de sociología de las elites en Chile (1990-2010). Santiago: Ediciones Universidad Diego Portales. 
Keohane, R. (2001). Relaciones internacionales: lo viejo y lo nuevo. En R. Goodin y H. D. Klingemann (eds.), Nuevo manual de ciencia política. Tomo II (pp. 668-692). Madrid: Itsmo.

Keohane, R. y Nye, J. (1988). Poder e interdependencia: la politica mundial en transición. Buenos Aires: Grupo Editor Latinoamericano.

Klotz, A. y Linch, C. (2007). Strategies for Research in Constructivist International Relations. Nueva York: Routledge.

Kubálková, V. (2001). Foreign policy, international politics, and constructivism. En V. Kubálková (ed.), Foreign Policy in a Constructed World (pp. 15-37). Nueva York: Routledge.

Lasagna, M. (1995). Las determinantes internas de la política exterior: un tema descuidado en la teoría de la política exterior. Estudios Internacionales, Universidad de Chile, 28(111), 387-409.

Lasagna, M. (1996). Cambio institucional y política exterior: un modelo explicativo. Afers Internacionals, (32), pp. 45-64. Recuperado de https://core.ac.uk/ download/pdf/39007711.pdf

Lizama, N. (2013). El constructivismo como nueva perspectiva para analizar las relaciones entre Estados: El caso de la crisis del gas entre Bolivia y Chile. Revista Universum [en línea], 28(2), 83-102. Recuperado de https://scielo.conicyt.cl/scielo.php?script=sci_arttext\&pid=S0718-23762013000 200005

Meyer, L. (1995). Liberalismo autoritario. Las contradicciones del sistema político mexicano. México: Ed. Océano de México.

Nye, J. (2002). The Paradox of American Power: Why the World's only Superpower Can't Go It Alone. Oxford: Oxford University Press.

Palacios, J. J. (1995). El nuevo regionalismo latinoamericano: el futuro de los acuerdos de libre comercio. Comercio Exterior, 45(4), 295-302.

Porcelli, E. (2013). Lo esencial es invisible a los ojos. El constructivismo en las relaciones internacionales. En E. Llenderrozas (coord), Relaciones internacionales: teorías y debates (pp. 65-105). Buenos Aires: Eudeba.

Portales, C. (2011). La (re)construcción de la identidad internacional de Chile. La política multilateral de la Concertación (1990-2010) y los nuevos desafíos para la política exterior. ICSO-UDP, Working Paper. Recuperado de https://www.icso.cl/wp-content/uploads/2012/01/Working-Paper-ICSO-Taller4..pdf

Price, R, y Reus-Smit, Ch. (1998). Dangerous Liaisons? Critical International Theory and Constructivism. European Journal of International Relations, 4(3), 259-294. 
Rivera, E. (7 de mayo de 2014). Böeninger, consensos y transformación económicosocial. El Mostrador, s. p. [En línea]. Recuperado de https://www.elmostrador.cl/ noticias/opinion/2014/05/07/boeninger-consensos-y-transformacion-economicosocial/

Rojas, F. (1997). Chile: cambio político e inserción internacional 1964-1997. Estudios Internacionales, Universidad de Chile, 30(119-120), 376-406.

Rovira K., C. (2007). Chile: transición pactada y débil autodeterminación colectiva de la sociedad. Revista Mexicana de Sociología, 69(2), 343-372.

Rudra, S. y Katzenstein, P. J. (2010). Beyond Paradigms. Analytic Eclecticism in the Study of World Politics of Political Analysis. Londres: Palgrave Macmillan.

Sánchez, L. E. (2012). ¿De qué se habla cuando se habla de constructivismo? Revisión de sus clasificaciones y categorías. Revista de Relaciones Internacionales de la UNAM, (114), pp. 107-129. Recuperado de http://www.memoria.fahce. unlp.edu.ar/art_revistas/pr.10017/pr.10017.pdf

Van Klaveren, A. (1998) Inserción internacional de Chile. En C. Tolosa y E. Lahera (eds.), Chile en los noventa. (pp. 117-160.). Santiago: Presidencia de la República.

Vargas, F. (22 de enero de 2014). Asesor de relaciones internacionales de Bachelet cuestiona política exterior de Piñera. Emol, s. p. [En línea]. Recuperado de http://www.emol.com/noticias/nacional/2014/01/22/641044/asesor-de-

relaciones-internacionales-de-bachelet-cuestiona-politica-exterior-de-pinera.html

Vitelli, M. (2014). Veinte años de constructivismo en relaciones internacionales. Del debate metateórico al desarrollo de investigaciones empíricas. Una perspectiva sin un marco de política exterior. Revista POSTData. Revista de Reflexión y Análisis Político, 19(1), 129- 162.

Volgy, T. y Schwarz, J. (1991). Does politics stop at the water's edge? Domestics political factors and foreign policy restructuring in the cases of Great Britain, France, and West Germany. Journal of Politics, 53(3), 615-643.

Wendt, A. (1995). Constructing international politics. International Security, 20(1), 7181.

Wendt, A. (2005). La anarquía es lo que los Estados hacen de ella: construcción social de la política de poder. Revista Académica de Relaciones Internacionales, 46(2), 57-103.

Wilhelmy, M. (2015). Los empresarios y la política exterior. En M. Artaza y C. Ross (eds), La política exterior de Chile, 1990-2009: del aislamiento a la integración global. Vol. 2 (pp. 57-78). Santiago: Ril Editores.

Yamazawa, I. (21 de diciembre de 1994). APEC: lo que viene. Diario La Época. 